\title{
Utilization of Syndromic Surveillance to Identify Naled-Related IIIness in Florida
}

\author{
Prakash R. Mulay* \\ Florida Department of Health, Tallahassee, FL, USA
}

\section{Objective}

To describe the use of Florida Poison Information Center Network (FPICN) and Electronic Surveillance System for the Early Notification of Community-based Epidemics (ESSENCE-FL) emergency department (ED) chief complaints data to identify acute naled-related illness following aerial spraying in Miami-Dade county, Florida in response to the Zika outbreak.

\section{Introduction}

Pesticide-related illness and injury is a reportable condition in Florida. In August and September 2016, aerial spraying for mosquito control was conducted in an effort to reduce the population of Aedes aegypti mosquitoes in Miami-Dade County. ${ }^{1}$ Two areas Wynwood (in August) and Miami Beach (in September) were sprayed with naled. Naled is an organophosphate insecticide registered with the U.S. Environmental Protection Agency (EPA) which is applied via aerial ultra-low volume (ULV) spraying. In addition to routine surveillance using FPICN and reportable disease surveillance data to identify acute naled-related illness, the Florida Department of Health (DOH) also monitored ED chief complaints data to identify any associated increase in ED visits.

\section{Methods}

In 2016, DOH used three datasets to monitor illness related to naled exposure: FPICN call data, reportable disease (Merlin) data, and ED chief complaints. Product code 2327991 was used to search FPICN data for naled-related exposure calls. FPICN calls with the following medical outcomes were excluded: no health effect, not followed judged as nontoxic exposure, unrelated effect, and confirmed nonexposure. Individuals who met the reportable disease surveillance case definition for pesticide-related illness and injury ${ }^{2}$ were entered into Merlin. ESSENCE-FL was monitored to evaluate ED visits in Miami-Dade County for the syndrome categories and free text chief complaints involving eyes (free text queries for eye irritation, eye burning, eye redness, and conjunctivitis), skin (syndrome category for rash), and respiratory (sub-syndrome categories for shortness of breath, wheezing, acute bronchitis, sore throat, and asthma) illnesses.

\section{Results}

Twenty-two exposure calls were identified through FPICN data in 2016. Seven calls were excluded after DOH review determined that these individuals were not exposed to naled. Fifteen exposure calls were investigated and eight individuals met the surveillance case definition for pesticide-related illness and injury. Among the eight DOH cases, one individual was exposed in August (12.5\%), and seven in September (87.5\%). Everyone had low severity illness, five $(62.5 \%)$ were female, and the mean age was 39.6 years (range: 27 to 46 years). Two cases (25\%) were work-related. Review of ESSENCE ED chief complaints data for eye, skin, and respiratory illnesses showed a few statistically significant increases in daily patient visits. However, these increases were not attributed to aerial spraying.

\section{Conclusions}

FPICN data are useful in identifying cases of naled-related illness. Near real-time access to ED chief complaints data along with FPICN and Merlin data has enhanced surveillance capability for DOH and helped address public health concerns related to naled-related illness following aerial spraying in Miami-Dade County.

\section{Keywords}

Pesticide; Naled; Poison Center; ESSENCE; Surveillance

\section{References}

1. Likos A, Griffin I, Bingham AM, et al. Local Mosquito-Borne Transmission of Zika Virus-Miami-Dade and Broward Counties, Florida, June-August 2016. MMWR Morb Mortal Wkly Rep 2016;64:1032-8.

2. CDC. Case definition for acute pesticide-related illness and injury cases reportable to the national public health surveillance system. Cincinnati, OH: US Department of Health and Human Services, CDC; 2012. Available at http://www.cdc.gov/niosh/topics/pesticides/pdfs/ casedef.pdf.

\section{*Prakash R. Mulay}

E-mail: Prakash.Mulay@flhealth.gov 